\title{
A EXPERIÊNCIA DA MULHER HOSPITALIZADA COM O RECÉM-NASCIDO NA UNIDADE DE TERAPIA INTENSIVA NEONATAL
}

\section{THE EXPERIENCE OF THE HOSPITALIZED WOMAN WITH THE NEWBORN IN NEONATAL INTENSIVE THERAPY UNIT}

\section{LA EXPERIENCIA DE LA MUJER HOSPITALIZADA CON RECIÉN NACIDO EN NEONATAL UNIDAD DE CUIDADOS INTENSIVOS}

Ludimila Laranjeiras Barros Rocha ${ }^{1}$, Erika da Silva Dittz ${ }^{2}$, Elysangela Dittz Duarte ${ }^{3}$, Patricia Rodrigues da Costa ${ }^{4}$.

\begin{abstract}
RESUMO
Objetivo: Conhecer a experiência das puérperas de risco, hospitalizadas com o filho recém-nascido internado na unidade de terapia intensiva neonatal. Método: Trata-se de uma pesquisa com abordagem qualitativa, de caráter exploratório. Participaram do estudo nove puérperas de risco, hospitalizadas. A coleta de informações ocorreu por meio de entrevista semi-estruturada e observação participante, analisadas conforme referencial da Análise de Conteúdo. Resultados: Emergiram 3 categorias temáticas: as relações estabelecidas durante a hospitalização; a rede de apoio tecida pela puérpera de risco; os desafios enfrentados pela puérpera de risco. Conclusão: Durante o processo de internação da puérpera de risco e do seu recém-nascido, essa enfrenta desafios que abrangem a lida com as mudanças de percurso do parto, do nascimento e da construção da sua maternidade, impostas pela sua condição clínica e do seu recém-nascido. O estudo aponta a necessidade de construção e fortalecimento de ações de cuidado voltadas ao bem-estar da puérpera de risco, hospitalizada e com o filho recém-nascido internado na unidade de terapia intensiva neonatal.
\end{abstract}

Descritores: Saúde materna; Recém-nascido; Unidades de terapia intensiva neonatal; Relações mãe-filho; Poder familiar.

\begin{abstract}
Objective: To know the experience of puerperal risk patients hospitalized with the newborn child hospitalized in the neonatal intensive care unit. Method: This is a research with a qualitative, exploratory approach. Study participants were nine risk mothers hospitalized. Data collection occurred through semi-structured interviews and participant observation, analyzed according to the Content Analysis framework. Results: Three thematic categories emerged: relationships established during hospitalization; the support network woven by the puerperal woman at risk; the challenges faced by the puerperal woman at risk. Conclusion: During the hospitalization process of the puerperal women and her newborn, she faces challenges that deal with the changes in the course of delivery, her maternity birth and construction, imposed by her clinical condition and her newborn. The study points out the need build and strengthen care actions of the well-being of hospitalized risk puerperal woman and with her newborn child hospitalized in the neonatal intensive care unit.
\end{abstract}

Keywords: Maternal health; Infant newborn; Neonatal intensive care units; Mother-child relationships; Parenting responsability.

\section{RESUMEN}

Objetivo: Conocer la experiencia de las puérperas, en riesgo, hospitalizadas con el niño recién nacido hospitalizado en la unidad de cuidados intensivos neonatales. Métodos: Se trata de una investigación con enfoque cualitativo, desde la perspectiva de un estudio exploratorio. Los participantes del estudio fueron nueve puérperas de riesgo, hospitalizadas. La recolección de datos ocurrió por medio de entrevistas semiestructuradas y observación participante, analizadas de acuerdo a referencia del Análisis de Contenido. Resultados: Surgieron tres categorías temáticas: las relaciones establecidas durante la hospitalización; la red de apoyo tejida por el riesgo de las mujeres después del parto; los desafíos que enfrentan las puérperas en riesgo. Conclusión: Durante el proceso de internación de la puérpera de riesgo y de su niño recién nacido, ella enfrenta desafíos que abarcan el tratamiento con los cambios de recorrido del parto, del nacimiento y de la construcción de su maternidad, impuestas por su condición clínica y de su recién nacido. El estudio señala la necesidad de la construcción y el fortalecimiento de las acciones de cuidado del bienestar de la puérpera en riesgo después del parto, hospitalizada y con su niño recién nacido hospitalizado en la unidad de cuidados intensivos neonatales.

Descriptores: Salud materna; Recién nacido; Unidades de cuidado intensivo neonatal; Relaciones madre-hijo; Responsabilidad parental.

${ }^{1}$ Graduada em Terapia Ocupacional. Mestranda em Cuidar em Saúde pela Escola de Enfermagem da Universidade Federal de Minas Gerais. ${ }^{2}$ Graduada em Terapia Ocupacional. Pós-doutora em Ciências da Reabilitação pela Universidade Federal de Minas Gerais. ${ }^{3} \mathrm{G}$ raduada em Enfermagem. Pós-doutora pela School of Nursing/UNCChapel Hill. Docente na Universidade Federal de Minas Gerais. ${ }^{4}$ Graduada em Terapia Ocupacional. Mestre em Ciências da Saúde pela Universidade Federal de Minas Gerais. 


\section{INTRODUÇÃO}

Embora a gestação seja um fenômeno fisiológico e sua evolução se dê na maioria dos casos sem intercorrências, há uma parcela pequena de gestantes que, por características particulares, apresenta maior probabilidade de evolução desfavorável, tanto para o feto como para a mãe, constituindo o grupo chamado de gestantes de alto risco ${ }^{(1)}$.

Para além dos aspectos fisiopatológicos, a literatura aponta a necessidade de se considerar os aspectos psicoemocionais quando se trata de uma gestação de alto risco, uma vez que as inseguranças, dúvidas e medos podem ser potencializados por se tratar de um evento que coloca em risco a vida da mãe e do recémnascido ${ }^{(2-3)}$.

Ao término de uma gestação considerada de alto risco, o puerério - compreendido como o período do ciclo grávido-puerperal, em que as modificações locais e sistêmicas, provocadas pela gravidez e parto no organismo da mulher, retornam à situação do estado pré- gravídico ${ }^{(4)}$ nem sempre está isento dos riscos. Incertezas quanto ao bem-estar materno podem se manter após o parto e, por vezes, associado às incertezas quanto à vida do filho. A condição de saúde materna, como a ruptura prematura de membranas e doenças hipertensivas, apresenta forte associação com recém-nascidos que necessitam de cuidados na Unidade de Terapia Intensiva Neonatal (UTIN) ${ }^{(5)}$.

Sentimentos como medo de perder o filho, luto pela perda da gravidez normal, preocupações com a família, com a questão financeira e o trabalho, associados à necessidade de apoio em suas atividades de vida diária passam a fazer parte do cotidiano dessa mulher ${ }^{(6)}$. Cabe ressaltar que, neste estudo, o termo "puérpera de risco" relaciona-se à mulher que está em uma condição de risco relacionada à gestação de alto risco e demanda cuidados pós-parto diferentes dos habituais, necessitando de internação em unidade de cuidado especializada.

Quando a gestação de alto risco acarreta o nascimento de uma criança prematura que demanda sua internação, a mulher vivencia um espectro de emoções que vão desde o tédio à ira.
Sentimentos como frustração, tristeza, esperança, irritação, impaciência, culpa, medo, insegurança e ansiedade são relatados por elas ${ }^{(2,6)}$. Portanto, a hospitalização da puérpera de risco associada à hospitalização de seu filho na UTIN pode contribuir para uma vivência ainda mais desafiadora para a díade mãe e filho, por fragilidade física e emocional, e o distanciamento de seu filho.

Em meio a esse contexto adverso, da-se o processo de construção da maternidade. Em resposta a essa situação, o período em que a mulher se recupera fisicamente, adquire habilidades para cuidar e ler os sinais de sua criança, fortalece a relação mãe-filho, e tem como referência o modo de cuidar de outras pessoas mais experientes, pode ser potencialmente desafiador ${ }^{(7)}$.

Dentro desse contexto surgiram os questionamentos que orientaram este estudo: Qual é a vivência da puérpera de risco hospitalizada com o filho recém-nascido internado na UTIN? Quais os desafios vivenciados pela puérpera no que se refere aos cuidados com ela mesma e com o filho recém-nascido hospitalizado?

A internação simultânea de mãe-puérpera de risco e seu filho após o parto, delineam um contexto de cuidado com necessidades de saúde específicas. Faz-se necessário que seja considerada tanto a condição da puérpera de risco quanto do seu filho, que demandam cuidado diferenciado. Os estudos têm explorado a internação de um dos componentes da díade, sendo incipientes em abordar a internação concorrente de mães e seus filhos logo após o nascimento ${ }^{(6,8-10)}$. Verifica-se, portanto, a necessidade de que sejam exploradas as situações nas quais mãe e filho demandam cuidados diferenciados após o parto e nascimento. Acredita-se que os achados podem indicar os desafios por eles enfrentados, contribuindo para a qualificação da prática profissional e organização dos serviços de saúde.

$O$ estudo teve como objetivo conhecer a experiência das puérperas de risco hospitalizadas com o filho recém-nascido internado na Unidade de Terapia Intensiva Neonatal. 


\section{MÉTODO}

Trata-se de uma pesquisa com abordagem qualitativa, de caráter exploratório, realizada na Unidade de Gestação de Alto Risco (UGAR) de uma Instituição filantrópica de direito privado, especializada na assistência materno-infantil, localizada em Belo Horizonte, Minas Gerais. Essa unidade destina-se ao atendimento das gestantes de alto risco e puérperas que apresentam algum tipo de agravo relacionado à gestação e ao parto e requerem cuidados especiais. Juntamente à atuação da equipe médica e de enfermagem, a equipe multiprofissional também realiza atendimentos de acordo com as necessidades das pacientes.

A opção pelo referencial teórico da dialética deve-se ao fato de possibilitar apreender uma realidade marcada por contradições e que está constantemente em transição ${ }^{(11)}$. Pelo exposto, ao tomar como objeto de estudo a experiência das puérperas de risco hospitalizadas com o filho recém-nascido internado na UTIN, buscou-se apreender as contradições da realidade vivida por elas no decorrer da hospitalização. Partiu-se do princípio de que as puérperas são seres humanos que existem em um determinado tempo e espaço, estabelecem relações e estão inseridas em uma realidade social que se encontra em contínua transformação.

Foi realizada a busca ativa pelos participantes nas passagens de plantão da unidade e leitura dos prontuários. Incluiram-se nove (09) puérperas internadas na UGAR, com histórico e diagnóstico que caracterizava a gestação como sendo de alto risco, seus recémnascidos internados na UTIN da mesma instituição, e que apresentavam estabilidade clínica e condições para a realização da entrevista. Durante o período de produção dos dados, 22 puérperas estiveram internadas na unidade estudada, entretanto 8 receberam alta da unidade para a enfermaria no mesmo dia de internação, não sendo possível abordá-las e observá-las; 2 foram transferidas para outro hospital devido a complicações clínicas; 1 apresentou alteração na visão após o parto, não sendo possível realizar a leitura do Termo de Consentimento e, portanto, não aceitando assinálo; 1 cujo recém-nascido foi a óbito; e 1 era menor de idade e sem um acompanhante para responder legalmente por ela.

Como instrumentos, foram adotadas a entrevista semi-estruturada e a observação participante, após a realização de um teste piloto.
As questões norteadoras da entrevista foram: "Como está sendo a experiência de estar internada ao mesmo tempo em que seu bebê está na UTIN?; Quais os sentimentos você tem vivenciado neste momento?; Com o apoio de quem você pode contar neste momento?; Como você e sua família estão lidando com a situação de você e seu filho estarem internados?; 0 que tem Ihe ajudado a lidar com este momento? E o que tem dificultado?; Você tem participado dos cuidados do seu filho? Como?". Foram também coletadas informações relacionadas à identificação social materna, histórico familiar, histórico gestacional, condições clínicas da puérpera e do recém-nascido.

As observações aconteceram em diferentes horários, dias e espaços da instituição, de acordo com a rotina de cuidado das puérperas e recémnascidos. A coleta de dados foi realizada no período de fevereiro a abril de 2013, sendo finalizada pelo critério de saturação de dados ${ }^{(12)}$.

Para garantir a privacidade da puérpera, a abordagem foi realizada individualmente e em ambiente reservado. As entrevistas foram gravadas e, posteriormente, transcritas e submetidas à análise de conteúdo, sendo utilizada a modalidade temática ${ }^{(12)}$. Com a aplicação da técnica, foi realizada a leitura flutuante para apreender e organizar, de forma não estruturada, aspectos importantes para as próximas fases da análise; a seleção das unidades de análise, identificando unidades de registro que vislumbrem o objetivo da pesquisa; e a categorização, sendo definidas categorias que abarcam temas variados, os quais foram agrupados por similaridade permitindo a identificação de três categorias empíricas ${ }^{(12)}$ : as relações estabelecidas durante a hospitalização; a rede de apoio tecida pela puérpera de risco; os desafios enfrentados pela puérpera de risco. Posteriormente, foram realizadas as inferências, a interpretação dos resultados encontrados e a discussão, à luz da literatura, pertinente ao tema ${ }^{(12)}$.

O estudo foi realizado em consonância com as diretrizes regulamentadoras de pesquisas, envolvendo seres humanos, Resolução 466/2012 do Ministério da Saúde, e foi submetido e aprovado pelo Comitê de Ética em Pesquisa do Hospital, cenário do estudo (Parecer no 179.788). Foram dadas, às participantes, as informações sobre o estudo e, no que consistia a sua participação, a garantia de preservação do anonimato e confidencialidade das informações e 
de que não haveria nenhum comprometimento para a assistência prestada ao recém-nascido ou a ela. Todas as puérperas abordadas aceitaram participar do estudo e assinaram o Termo de Consentimento Livre e Esclarecido. Para a preservação do anonimato, adotou-se a seguinte codificação: participantes (M), pediatra (PD), enfermeiro obstetra (EO) e técnico de enfermagem da Neonatologia (TEN). Para identificar o instrumento utilizado para a coleta de dados, adotou-se o código OP para observação participante e E para entrevista, seguido da ordem de aparecimento do trecho na entrevista ou da cena observada e, nos casos da observação, o horário da sua realização (Ex.: M5-OP1122:35h).

\section{RESULTADOS E DISCUSSÃO}

Participaram do estudo, 9 puérperas com idade entre 18 e 33 anos, das quais 7 (sete) eram casadas ou possuíam união estável e vindas do interior de Minas Gerias. Em 6 (seis) casos, o recém-nascido internado no momento era o primeiro filho da mulher. Com relação às gestações anteriores, 3 (três) das participantes apresentavam histórico de gestação de alto risco, das quais, 2 (duas) tiveram outros recém-nascidos internados na UTIN. Apenas uma participante não teve 0 recém-nascido pré-termo. $A$ idade gestacional dos demais recém-nascidos variou de 29 semanas e 2 dias a 34 semanas e 5 dias. Sete mulheres evoluíram para parto cesáreo.

Quanto ao tempo de internação hospitalar até a alta da UGAR, a permanência variou de 1 a 16 dias. Dentre os motivos de internação, estavam o sangramento aumentado, a préeclâmpsia grave, Síndrome Hellp e descolamento prematuro de placenta.

\section{As relações estabelecidas durante a hospitalização}

A puérpera de risco demanda cuidados especializados e apoio para realizar os cuidados com o filho, necessitando de maior suporte e contato com a equipe de saúde.

Frente ao contexto de gravidade, a puérpera estabelece uma relação de segurança e de confiança com a instituição, ao perceber que, nela, existem os recursos necessários para assistila e para atender às necessidades de saúde do filho recém-nascido, como profissionais capacitados e aparato tecnológico:

"Saber que eu estou em um lugar seguro, que eu não estou em qualquer lugar! Se, Deus me livre, eu ganhasse lá na minha cidade, poderia acontecer alguma coisa comigo ou com o bebê. Eu estou me sentindo muito bem de saber que eu estou em um lugar seguro." (M1-E10)

Essa relação de confiança na equipe é importante ser estabelecida, pois a ausência de suporte ou acompanhamento apropriado pode desencadear insegurança, fantasias e dúvidas sobre o atendimento oferecido ${ }^{(13)}$.

$O$ fato de o recém-nascido e da puérpera demandarem cuidados especializados, configurase como um limite para o contato entre mãe e filho nos momentos iniciais após o nascimento. Adicionado a isso, a dor física, a dificuldade de se locomover, a fraqueza e os efeitos do uso da medicação são aspectos que, ora dificultam, ora impedem que as puérperas fiquem junto do filho na UTIN.

"O que tem dificultado é eu não poder levantar e ir lá vê-lo, porque ele está na UTI e eu estou internada também, então é difícil mesmo. Também, não é qualquer hora que eu posso levantar, sair andando e ir lá". (M7-E10)"

As condições clínica e de internação da mulher modificam a vivência da maternidade nessa fase inicial. Ao demandar cuidados especializados para reestabelecer sua condição, a puérpera passa a ser mais um objeto de cuidado do que alguém que tem condições de cuidar do filho.

O período imediatamente após a admissão do recém-nascido na UTIN pode ser um dos mais estressantes para as mães ${ }^{(14)}$, causando apreensão e prejudicando o estabelecimento do vínculo ${ }^{(15)}$. Quando a situação de risco envolve tanto a puérpera quanto o recém-nascido, com consequente internação em unidades assistenciais distintas, esses sentimentos negativos podem ser intensificados.

Embora a mulher esteja em uma unidade de cuidados intensivos, mais do que apenas recuperar a sua condição clinica, há também a necessidade de estabelecer cuidados de apoio.

Portanto, é recomendado que um profissional da equipe possa visitar a mãe ainda em sua unidade de internação, transmitindo notícias sobre o recém-nascido. Essa conduta faz com que ela se sinta mais confiante com a equipe, e que algumas de suas inquietações sejam minimizadas ou sanadas ${ }^{(9,13)}$. Uma estratégia para favorecer o contato entre mãe e filho, quando não é possível para puérpera ir à UTIN, é fazer uso de fotografias do recém-nascido ${ }^{(9)}$. 
Além da ansiedade, sentimentos como medo, estresse, impotência e culpa estão frequentemente relacionados às mulheres em condição de risco no ciclo gravídico puerperal, pela vulnerabilidade a que estão sujeitas a saúde materna e dos bebês ${ }^{(16-17)}$.

O presente estudo obteve, como achados, os sentimentos de impotência da puérpera diante da sua condição e a do filho, de ansiedade por notícias e a expectativa de um reencontro com seu recém-nascido.

Durante a internação da puérpera de risco, tão logo tenha condições clínicas, é incentivada a sua ida à UTIN. Esse acesso à UTIN possibilita à puérpera obter informações acerca do filho recém-nascido, bem como cria possibilidades para envolver-se em práticas de cuidado. Em algumas situações, a puérpera utiliza o toque, 0 olhar e a voz como forma de estar próxima e interagir com o filho.

“[...]PD1 explica sobre o quadro respiratório do bebê, [...] também orienta quanto à extração manual do leite, onde fica a sala de coleta e pede que a própria mãe solicite na UGAR mais orientações. Ao final, confirma novamente com M2 se havia entendido as informações, a qual afirma que sim". (M2-OP7- 10:00h)

"[...] A mãe volta ao leito do filho, encurvase para frente aproximando-se do rosto do recém-nascido e oferece o seu dedo para que o bebê segure. $\mathrm{M} 2$ passa a conversar com o filho, que se acalma e abre os olhos". (M2-OP14- 9:20h)

Estimular o livre e precoce acesso da mãe à UTIN favorece o estabelecimento da relação mãefilho ${ }^{(13)}$. Vale ressaltar que a instituição onde foi realizado o estudo permite aos pais acesso livre à UTIN. Tal aspecto possibilita momentos de contato entre mãe-filho tão logo a puérpera tenha condições de ir à unidade, o que pode contribuir para o fortalecimento do vínculo e para oportunizar a participação da mãe no cuidado de seu filho.

Na primeira visita à UTIN, após os pais conhecerem o ambiente e perceberem que o recém-nascido está recebendo todo o tratamento necessário, eles sentem-se seguros para confiar os cuidados do filho à equipe de saúde ${ }^{(13)}$. Assim, faz-se necessário que o profissional de saúde oriente a mãe e a família de forma clara e objetiva quanto aos aparelhos ligados ao recém-nascido, aos cuidados de que ele necessita, quanto ao prognóstico, e quanto à rotina da unidade.

As puérperas valorizam as oportunidades de acompanharem o cuidado do recém-nascido realizado pela equipe. Observa-se que, na relação estabelecida entre o profissional de saúde e a puérpera, o esclarecimento de dúvidas acerca das condições de saúde do recém-nascido pelo profissional favorece a construção de possibilidades para a puérpera se envolver e participar do cuidado com o filho na UTIN.

"[...]M5 permanece ao lado do berço olhando os procedimentos atentamente $e$ pergunta à profissional sobre o leite do filho. A técnica diz que está suspensa a dieta, mas reforça a importância de M5 extrair o leite para estimular a produção do mesmo e explica para a mãe onde fica a sala de coleta [...]. TEN7 pede para M5 mudar de lado e diz que vai colocar o bebê no colo da mãe para arrumar o berço". (M5-OP20 9:00h)

Apesar de a puérpera ter acesso às informações sobre o filho internado na UTIN, observam-se situações em que o diálogo estabelecido entre puérpera e profissional de saúde pode ficar comprometido devido à utilização de termos técnicos, ficando a informação incompreensível e inacessível para a primeira.

“[...] TEN5 liga o Bilispot $^{\circledR}$ e direciona o foco de luz para o bebê, explicando para M5 que o bebê está na luz porque sua pele está muito vermelha e que, com certeza, ele vai ter icterícia. M5 questiona o que é icterícia e obtém como resposta de TEN5 que é o aumento de bilirrubina no sangue" (M5-OP11- 22:35h)

Verifica-se ainda que estão presentes, no cotidiano da UTIN, as relações de poder que se estabelecem entre puérperas e profissionais de saúde, como nas situações em que o profissional é quem decide quando irá atender à necessidade de informação da mãe:

"Parada de frente para PD3, M5 diz: "você pode olhar se meu bebê está bem?". PD3 diz que não pode dar notícias no momento porque não está no horário de notícia". (M5-OP13 - 22:37h)

0 sofrimento vivenciado pelas puérperas pode ser exacerbado quando elas não obtêm informações sobre o recém-nascido internado na UTIN. Mal informadas, demonstram insegurança e ansiedade. Mesmo os profissionais de saúde tendo conhecimento acerca da importância de fornecer informação, sua oferta ainda é insuficiente, pouco esclarecedora e ocorre de acordo com a dinâmica da unidade e rotina do profissional e não pautada nas necessidades das mães ${ }^{(18)}$. Adicionado a esses aspectos, o abuso de termos técnicos e a desvalorização dos aspectos 
emocionais maternos pelos profissionais de saúde criam barreiras, favorecendo o distanciamento e conflitos nas relações entre mães e equipe ${ }^{(13)}$.

No atendimento à necessidade de informação das mães de recém-nascidos internados na UTIN, salienta-se a importância de respeitar e considerar a singularidade das necessidades não só do recém-nascido internado, mas também da puérpera em sua condição de hospitalização e de mãe desse recém-nascido. Portanto, é necessário que a equipe exercite a habilidade de escuta para potencializar a sua capacidade em responder a essas necessidades ${ }^{(6,8-}$ 10). Nesse sentido, nos encontros entre pais e profissionais, é importante o estabelecimento de uma relação dialógica, possibilitando que, na passagem de notícias, sejam atendidas as necessidades do profissional e dos pais de forma mais concreta ${ }^{(8)}$.

À medida em que a relação estabelecida entre a família e os profissionais de saúde permite um olhar ampliado, que considere as necessidades de construção e fortalecimento de vínculo, diálogo e acolhimento, é aberta a possibilidade da produção de um cuidado orientado pela integralidade ${ }^{(8)}$.

\section{A rede de apoio tecida pela puérpera de risco}

O estudo revelou como a rede de apoio dessas mulheres é ativada e redesenhada. Com a hospitalização da puérpera e do filho recémnascido, laços sociais encontram-se enfraquecidos, outros são fortalecidos, e novas relações de apoio vão se estabelecendo no cotidiano.

Desde a internação na gestação de alto risco, verifica-se a necessidade predominante de apoio social para essas mulheres, diante da separação dos familiares e sentimento de desligamento social ${ }^{(19)}$. Esse apoio continua sendo essencial para a puérpera de risco que permanece hospitalizada.

Os relatos evidenciam que a rede de apoio dessas puérperas é composta por familiares, vizinhos e amigos e que, mesmo distante geograficamente, este é um grupo com o qual elas contam. Vale ressaltar que a presença da figura materna parece ter maior destaque, uma vez que são as mães dessas puérperas quem as acompanham no processo de internação e, quando isso não é possível, essa ausência é sentida pelas puérperas:

"Eu estou contando com o apoio de todo mundo da minha família. Não estão todos aqui comigo, mas está todo mundo me apoiando, o dia inteiro me ligando". (M5-E1)

"[...] Agora que eu mais precisava dela [mãe], para poder ajudar a dar um banho, alguma coisa assim, não tem como ela vir!" (M6-E6)

Durante a hospitalização, os profissionais de saúde também passam a compor a rede de apoio à puérpera de risco. Evidencia-se que a puérpera reconhece $\mathrm{o}$ apoio oferecido pelos profissionais, especialmente nas situações em que as pessoas, com as quais ela esperava contar, não podem estar presentes.

"O que me ajudou foi o povo aqui [profissionais da saúde] ter conversado comigo, por que eu estava muito nervosa. [...] Porque se não fosse isso, eu estaria desesperadinha, sem saber o que fazer! É, para você ver, contando com os outros de fora, porque os de casa não têm como contar!" (M6-E7)

As redes sociais compreendem não apenas a família nuclear ou extensa, podendo ser definidas pela disponibilidade de apoio e reforço por sistemas ou pessoas significativas, diante de situações de crise, favorecendo estratégias de enfrentamento por meio de carinho, encorajamento ou assistência(20-21).

Num primeiro momento, a puérpera busca apoio nas pessoas com quem mantém maior convivência, como o companheiro e os familiares mais próximos ${ }^{(10,22)}$. Quando a mulher não encontra, nesse grupo, alguém que lhe apoie e acompanhe, o processo de internação torna-se mais difícil. Dessa forma, é importante que os profissionais de saúde sejam sensíveis às necessidades maternas e familiares durante o cuidado, sendo reconhecidos como fonte de apoio através de pequenos gestos ${ }^{(3,9-10)}$.

A ausência de apoio da equipe para envolvimento dos pais com os bebês na UTIN acarreta alto nível de estresse, ansiedade, prejudicial na internação e promoção de uma atenção integral ${ }^{(23)}$.

Cabe ressaltar que a maioria das participantes do estudo eram provenientes de cidades do interior do Estado, que não dispunham de recursos para atender as suas necessidades de saúde e de seu recém-nascido. Nesse sentido, há que se considerar a necessidade de as instituições de saúde assegurarem às puérperas e recémnascidos o direito ao acompanhante, contribuindo para a minimização do distanciamento entre mãe, recém-nascido e familiares, decorrente do período de internação. 
A permanência do acompanhante durante a internação possibilita que esse ofereça apoio emocional à puérpera, bem como a auxilie nas atividades de autocuidado e nos cuidados do filho internado. Somado a isso, em algumas situações, o acompanhante dá voz às necessidades da puérpera e facilita o acesso às informações sobre o filho internado na UTIN.

"M2 queixa dor na barriga e diz não conseguir subir para a sala de coleta para ordenhar. A acompanhante vai ao posto de enfermagem, dirige-se à EO1 e explica que, na UTIN, pediram que M2 retirasse o leite para oferecer ao bebê, mas que ela não conseguirá subir até a sala de coleta devido à dor e fraqueza". (M2-OP10- 10:40h)

"M1 diz que o filho está bem e que, como não está conseguindo subir, às 11:00 horas, o marido vai até à UTIN receber a notícia. Relata ainda que o marido fotografou o filho para mostrá-la". (M1-OP1- 10:55h)

Tanto a fé quanto o filho internado na UTIN surgem como elementos constituintes dessa rede de apoio, possibilitando às puérperas sentirem-se fortalecidas para superar a situação vivenciada.

"É só Deus e ela [filha recém-nascida], porque eu tenho que estar forte para cuidar dela. Então, só assim que a gente tem força para superar essa fase". (M8-E4)

Mulheres que vivenciam situação semelhante constituem fonte de apoio para a puérpera, especialmente para que ela se adapte às rotinas de cuidado relacionadas ao recémnascido internado na UTIN.

"Na sala de coleta, M4 pergunta para outra puérpera que retirava o leite ao seu lado, como fixar a etiqueta de identificação na seringa e pede que the lembre o nome do lugar onde deve levar o leite. A puérpera diz estar indo para o lactário e que se M4 quiser podem ir juntas [...]". (M4OP14- 19:00h)

Este reconhecimento dos sentimentos em outras puérperas em situação similar faz com que as mulheres não se sintam sozinhas e percebam que podem se apoiar durante esta trajetória ${ }^{(10)}$. As redes sociais possuem características que envolvem variáveis de sua estrutura, sua funcionalidade e dos atributos de seu vínculo(20). Com base nessa caracterização, dentre as diversas funcionalidades da rede, pode-se considerar que a puérpera de risco e o filho internado na UTIN necessitam, em especial, de uma rede cuja função seja o apoio emocional.
Portanto, podem se configurar, como estratégias de ampliação e fortalecimento dessa rede de apoio, a criação de grupos de apoio para as mães, conduzidos por meio da abordagem educativa, de suporte psicoemocional e social. A estratégia de grupos de apoio é uma prática implantada na instituição, cenário deste estudo. Diferentes modalidades de grupos de apoio são oferecidas às mães de recém-nascidos internados na UTIN pela equipe multiprofissional ${ }^{(8)}$. Entretanto, atentamos para o fato de que as puérperas de risco, internadas na UGAR e com o filho na UTIN, ainda não são inseridas nessa modalidade de assistência.

\section{Os desafios enfrentados pela puérpera de risco}

A internação da puérpera de risco e do filho recém-nascido gera mudanças que podem configurar-se como desafios a serem enfrentados pela puérpera. Um deles refere-se à mudança no curso de sua gestação, quando ela se vê frente à necessidade de lidar com a frustração diante das expectativas não atendidas e elaborar uma nova realidade, por vezes distante da anteriormente imaginada:

"Frustrante demais! Eu esperava ganhar, recuperar e ir embora. Mas estou tentando ficar calma agora". (M2-E1)

Esse desafio pode estar relacionado ao fato de que, quando a mulher é uma gestante de alto risco, o seu processo de parto tende a ser focado prioritariamente em procedimentos médicos voltados para ela e para o recém-nascido, em detrimento de seus sentimentos, valores e crenças serem levados em consideração desde o pré-natal até o momento do nascimento ${ }^{(3,10)}$. Além do modo como transcorre o parto e o nascimento, tem-se ainda o fato de o filho ser prematuro ou demandar cuidados intensivos.

A internação da puérpera e do recémnascido em unidades distintas apresenta-se como uma situação geradora de sofrimento para a mulher, estabelecendo limites para que ela possa cuidar e interagir com seu filho, como é expresso no relato a seguir:

"A distância dificulta tudo porque, se ela estivesse aqui pertinho, eu podia estar toda hora olhando. [...]. Eu acho que preocupação faz a gente ficar pior! Porque, com ansiedade, a gente não descansa. Essa noite mesmo, eu não dormi nada, preocupada!" (M8-E5)

"[...] quando você ganha uma criança de parto normal, logo você já pega. E, ontem, eu não pude, porque é prematuro e você não pode pegar 
[...] é diferente, é estranho! Nem sei te explicar!" (M6-E5)

Essa dificuldade encontrada pela puérpera para estar mais tempo próxima e ter oportunidades de interagir com seu filho é intensificada pelas limitações apresentadas pelo recém-nascido internado na UTIN, como a instabilidade clínica e habilidades ainda imaturas para envolver-se em uma interação, sendo difícil o reconhecimento e interpretação de seu comportamento pela mãe ${ }^{(15)}$.

Ao saber que seu filho nascerá prematuro, a gestante de alto risco vivencia o sentimento de apreensão que, no puerpério de risco, dá lugar aos sentimentos de ansiedade, incertezas e medo frente ao nascimento prematuro e a sua condição de saúde. O conhecimento de pertencer a um grupo de risco torna a mulher mais propensa ao desgaste ou estresse psicológico ${ }^{(10)}$.

Assim, as puérperas de risco carecem ser confortadas e esclarecidas diante dos acontecimentos inesperados e ruins, e receber apoio no enfrentamento dos desafios atrelados ao puerpério de risco.

Outro desafio refere-se às condições de saúde da puérpera, que comprometem sua participação nos cuidados do filho, tais como alimentação, banho, troca de fralda e segurar no colo. Nessa situação, a puérpera reconhece suas limitações e busca cuidar de si a fim de ter condições para cuidar do filho.

"Eu tenho ido lá, tenho tirado o leitinho para ele, sempre que eu dou conta de levantar, eu vou lá ver ele, rezar para ele... Estou me cuidando para eu cuidar dele, tomando bastante água, comendo direito, para ficar forte e conseguir cuidar dele!" (M2-E7)

A impossibilidade de desempenhar as tarefas típicas de ser mãe é um fator de estresse em potencial para as mães, podendo influenciar negativamente na sua capacidade de aprender sobre os cuidados demandados pelo recémnascido e se preparar para assumir o cuidado ${ }^{(14)}$.

A construção da identidade materna é influenciada por fatores maternos como: a percepção da experiência de nascimento, separação precoce do filho, estresse, ansiedade, estado de saúde, percepção em relação a criança e conflito de papéis; por fatores pertinentes à criança, que abrangem a habilidade de dar sinais, estado de saúde e aparência; e fatores ambientais, incluindo o contexto familiar e suporte social ${ }^{(7)}$.
Nas situações em que a puérpera apresenta condições e expressa seu desejo de participar do cuidado do filho, nem sempre essa participação é favorecida pelo profissional de saúde.

“[...] TEN7 pega o bebê novamente e o coloca no berço, ele está chorando. TEN7 começa a higienizar o bebê, enquanto isso, por duas vezes M5 pega na mão do filho, mas com os manuseios da técnica, as mãos acabaram se afastando. M5 pergunta para a técnica se o limpa todos os dias nesse mesmo horário e explica, sorrindo, que quer acompanhar o cuidado todos os dias [...]" (M5-OP21- 9:00h)

Apesar da existência de um discurso em defesa da presença e participação da mãe/família na UTIN, essa presença pode ser vista como um problema para os profissionais de saúde, à medida que demanda que os profissionais dediquem-se a auxiliar na reorganização social, afetiva e psicológica dos pais ${ }^{(13)}$.

A possibilidade de a mãe participar dos cuidados na UTIN tem sido defendida, basendo-se no entendimento de que trará benefícios para a saúde do recém-nascido e contribuirá para segurança dos pais em relação ao cuidado do filho $^{(18)}$. Destaca-se a importância de estimular o contato materno com o neonato; a realização da posição canguru e a extração manual do leite ${ }^{(19)}$. É evidenciado ainda o imprescindível papel dos profissionais, especialmente de enfermagem, para aumentar a compreensão e o sentimento de participação materna no cuidado de seu filho ${ }^{(6,22,24)}$.

Pelo exposto, torna-se premente orientar as puérperas hospitalizadas, qualificando seu conhecimento acerca dos comportamentos do recém-nascido ${ }^{(25)}$ e trabalhar, com elas, a construção de possibilidades para o cuidado do filho recém-nascido durante a internação na UTIN, uma vez que muitas trazem consigo expectativas acerca do que é cuidar em uma situação de nascimento saudável e a termo, sendo necessário construir, também conjuntamente, alternativas de contribuição na situação de internação na UTIN. Esse processo de construção e descoberta de novas possibilidades é que irá favorecer a sua participação no cuidado do filho e amenizar o sentimento de perda do papel materno.

Considerando-se as interferências que a condição de saúde do recém-nascido têm na forma de enfrentamento dessa situação pela puérpera e a vivência da maternidade, faz-se necessário que, no processo de cuidado à 
puérpera de risco, sejam considerados os processos de adoecimento de mãe e filho.

Mesmo quando não apresentando condições clínicas, a puérpera deseja cuidar do filho. Nesses casos, recomenda-se a elaboração de orientações para uma prática profissional que criem condições para as mulheres que estão muito dependentes ou necessitam de cuidado intensivo para facilitar a visita ao seu bebê ou vice- versa ${ }^{(9)}$.

\section{CONSIDERAÇÕES FINAIS}

O estudo revelou como é a experiência da mulher hospitalizada com o recém-nascido internado na UTIN e como esse contexto transforma sua maternagem.

Durante o processo de internação da puérpera de risco e do seu recém-nascido, essa enfrenta desafios que abrangem a lida com as mudanças de percurso do parto, do nascimento e da construção da sua maternidade, impostas pela condição clínica sua e do seu recém-nascido. Tais desafios podem ser intensificados ou amenizados de acordo com fatores físicos e emocionais da mulher e a organização de sua rede de apoio, composta pelas relações que estabelece com o filho recém-nascido, a familia próxima, com outras mulheres em situação similar e com os profissionais de saúde.

Em destaque, quando os profissionais de saúde contribuem para que as necessidades da puérpera e as do recém-nascido sejam atendidas, eles passam a compor a rede de apoio da puérpera, tendo a função de fortalecê-la, principalmente quando outras fontes de apoio estão fragilizadas. Contudo, essa relação também se configura como desafiadora para 0 enfrentamento do processo de ambas as internações e para a participação da puérpera nos cuidados com o filho recém-nascido, à medida que o profissional de saúde não oferece a oportunidade de a mãe ser participativa e ativa na maternagem, e não estabelece um diálogo efetivo com a puérpera, em especial, sobre informações relacionadas ao recém- nascido.

Frente à compreensão das necessidades de saúde dessas puérperas, seus desafios e potenciais fontes de apoio, e considerando as propostas do Ministério da Saúde de melhoria da qualidade da atenção pré-natal, da assistência ao parto e puerpério, é premente a construção e fortalecimento de ações de cuidado voltadas ao bem-estar da puérpera de risco, seu recémnascido e família. Nessa perspectiva, é recomendado criar espaços de conversa para que as puérperas possam expressar seus sentimentos; favorecer o contato precoce entre puérpera e família com o recém-nascido na UTIN; criar possibilidades para puérpera participar do cuidado do filho; estabelecer um processo de comunicação no qual os profissionais de saúde estejam sensíveis às necessidades de informação da puérpera e família; investir na educação permanente dos profissionais de saúde, possibilitando a aquisição de conhecimentos com vistas a atender às necessidades de cuidado da puérpera de risco, seu recém-nascido e família.

Como uma limitação do estudo, destaca-se o fato de ter sido realizado em um único cenário. Ressalta-se que, para este estudo, buscou-se a perspectiva das mulheres e a coleta de dados foi realizada durante parte da internação. Sugere-se a realização de estudos que considerem a perspectiva de outros indivíduos, como familiares e profissionais da equipe de saúde. Estudos longitudinais podem investigar as diferentes fases da internação, bem como as repercussões dessa vivência em longo prazo para as puérperas e seus recém-nascidos.

\section{REFERÊNCIAS}

1. Ministério da Saúde. Gestação de alto risco: manual técnico. 5a ed. Brasília: Ministério da Saúde; 2012.

2. Martins LA, Camargo MJG. O significado das atividades de Terapia Ocupacional no contexto de internamento de gestantes de alto risco. Cad Ter Ocup UFSCar. 2014;22(2):361-71. DOI: 10.4322/cto.2014.056

3. Wilhelm LA, Alves CN, Demori CC, Silva SC, Meincke SMK, Ressel LB. Sentimentos de mulheres que vivenciaram a gestação de alto risco: estudo descritivo. Online Braz J Nurs. 2015 [citado em 12 mar 2017]; 14(3). Available in: http://www.objnursing.uff.br/index.php/nursing/ article/view/5206/html 882

4. Neme B. Obstetrícia básica. São Paulo: Sarvier; 2000.

5. Costa ALRR, Araújo Junior E, Lima JWO; Costa FS. Maternal risk factors associated with the necessity of neonatal intensive care unit. Rev Bras Ginecol Obstet. 2014;36(1):29-34. DOI: 10.1590/S0100-72032014000100007

6. Pieszak GM, Paust AM, Gomes GC, Arrué AM, Neves ET, Machado LM. Internação de recémnascidos prematuros: percepções dos pais e revelações acerca do cuidar de enfermagem. Rev 
Rene. 2017;18(5):591-7.

DOI: 10.15253/rev\%20rene.v18i5.30805

7. Mercer RT. Nursing support of the process of becoming a mother. J Obstet Gynecol Neonatal Nurs. 2006;35(5):649-51. DOI: 10.1111/j.15526909.2006.00086.x

8. Duarte ED, Dittz ES, Silva BCN, Rocha LLB. Grupos de apoio às mães de recém- nascidos internados em unidade neonatal. Rev Rene. 2013;14(3):630-8.

DOI:

10.15253/rev\%20rene.v14i3.3507

9. Hinton L, Locock L, Knight M. Experiences of the quality of care of women with near- miss maternal morbidities in the UK. BJOG 2014;121(Suppl 4):20-3. DOI: 10.1111/1471$\underline{0528.12800}$

10.Roque ATF, Carraro TE. Narrativas sobre a experiência de ser puerpéra de alto risco. Esc Anna Nery 2015;19(2):272-8. DOI: 10.5935/14148145.20150036

11.Demo P. Metodologia científica em ciências sociais. 3a ed. São Paulo: Atlas; 1995.

12.Minayo MCS. O desafio do conhecimento: Pesquisa qualitativa em saúde. 13a ed. Rio de Janeiro: HUCITEC-ABRASCO; 2013.

13. Ministério da Saúde. Atenção humanizada ao recém-nascido: Método Canguru: Manual técnico. 3a ed. Brasília: Ministério da Saúde; 2017.

14.Raines DA. Mothers' stressor as the day of discharge from the NICU approaches. Adv Neonatal Care. 2013;13(3):181-7. DOI: 10.1097/ANC.0b013e318285fa2a

15. Fleck P. Connecting mothers and infants in the neonatal intensive care unit. Newborn Infant Nurs Rev. 2016;16(2):92-6. DOI: 10.1053/j.nainr.2016.03.007

16.Souza NL, Araújo ACPF de, Costa ICC. Representações sociais de puérperas sobre as síndromes hipertensivas da gravidez e nascimento prematuro. Rev Latino-Am $\begin{array}{ll}\text { Enfermagem } & \text { 2013;21(3):1-8. DOI: }\end{array}$ 10.1590/S0104-11692013000300011

17.Avila WS, Figueiredo MR, Bortolotto L. Gestação em cardiopatias congênitas: visão do cardiologista e do obstetra. Rev Soc Cardiol Estado de São Paulo 2015;25(3):147-55.

18.Junqueira CCS, Machado SPC, Ventura CMU, Albuquerque TM, Machado AN, Nunes PM, et al. Paternal experience during the child hospitalization in neonatal intensive care unit. Int Arch Med. 2016;9(331). DOI: 10.3823/2202

19.Kent RA, Yazbek M, Heyns T, Coetzee I. The support needs of high-risk antenatal patients in prolonged hospitalisation. Midwifery 2015;31(1):164-9.

DOI:

10.1016/i.midw.2014.08.003

20.Sluzki CA. A rede social na prática sistêmica: alternativas terapêuticas. São Paulo: Casa do Psicólogo; 1997.

21.Brito RC, Koller SH. Desenvolvimento humano e redes de apoio social e afetivo. In: Carvalho AM (Org). O mundo social da criança: Natureza e cultura em ação. São Paulo: Casa do Psicólogo; 1999.

22.Oliveria K, Veronez M, Higarashi IH, Corrêa DAM. Vivências familiares durante a internação do filho. Esc Anna Nery 2013;17(1):46-53. DOI: 10.1590/S1414-81452013000100007

23.Magliyah AF, Razzak MI. The parents' perception of nursing support in their neonatal intensive care unit (NICU) experience. Int J Adv Comput Sci Appl. 2015; 6(2):153-158. DOI: 10.14569/IJACSA.2015.060222

24.Rocha SS, Olivindo DDF, Sá CN, Fonseca LF. Percepção da enfermagem em relação às mães no cuidado de recém-nascidos na unidade de terapia intensiva neonatal. Enferm Foco 2013;4(1):45-8. DOI: $\quad 10.21675 / 2357-$ 707X.2013.v4.n1.502

25.Dittz ES, Alves CRL, Duarte ED, Magalhães LC. Contribution of the Newborn Behavioral Observations (NBO) for the maternal care of preterm neonates. J Hum Growth Dev. 2017;27(3):262-71. DOI: 10.7322/jhgd.125522

Nota: Estudo extraído da monografia intitulada "A experiência da puérpera hospitalizada e com o filho recémnascido internado em uma unidade de terapia intensiva neonatal" do Curso de Especialização Multiprofissional em Neonatologia: ênfase em Terapia Ocupacional da Fundação Educacional Lucas Machado (FELUMA), oferecido em parceria com o Hospital Sofia Feldman.

Recebido em: 06/11/2017

Aprovado em: 16/07/2018

Endereço de correspondência:

Erika da Silva Dittz

Rua Antônio Bandeira, 1060 Bairro Tupi

CEP: 31 844-130 - Belo Horizonte/MG - Brasil

E-mail: erikadittz@gmail.com 